\title{
Obtenção biotecnológica de xilitol a partir de cavacos de eucalipto
}

\author{
Eliana Vieira Canettieri*, João Batista de Almeida e Silva , Maria das Graças de Almeida Felipe
}

Departamento de Biotecnologia, Faculdade de Engenharia Química de Lorena, Lorena

\begin{tabular}{|c|c|}
\hline $\begin{array}{l}\text { *Correspondência: } \\
\text { Eliana Vieira Canettieri } \\
\text { Departamento de Biotecnologia, } \\
\text { Faculdade de Engenharia Química de } \\
\text { Lorena } \\
\text { Rodovia Itajubá-Lorena, Km 74,5, } \\
\text { 12600-000, Lorena - SP , Brasil }\end{array}$ & $\begin{array}{l}\text { Cavacos de eucalipto foram submetidos à hidrólise ácida resultando } \\
\text { em um hidrolisado hemicelulósico rico em açúcares fermentesciveis. } \\
\text { O hidrolisado foi usado como meio de cultivo para o crescimento } \\
\text { da levedura Candida guilliermondii FTI } 20037 \text { para avaliar a } \\
\text { influência da suplementação do mesmo com os nutrientes sulfato } \\
\text { de amônio, cloreto de cálcio e farelo de arroz, bem como a } \\
\text { concentração de xilose no hidrolisado, o pH e o tempo de } \\
\text { fermentação na produção de xilitol. A formação de xilitol a partir } \\
\text { do hidrolisado hemicelulósico de cavacos de eucalipto foi } \\
\text { influenciada pela presença de sulfato de amônio e farelo de arroz, } \\
\text { pela concentração de xilose no hidrolisado e pH inicial de } \\
\text { fermentação. }\end{array}$ \\
\hline
\end{tabular}

\author{
Unitermos: \\ - Hidrolisado hemicelulósico \\ de eucalipto \\ - Candida guilliermondii \\ FTI 20037 \\ - Fermentação \\ - Xilitol
}

\section{INTRODUÇÃO}

A biomassa vegetal constitui uma fonte potencial de carbono e energia que pode ser empregada em bioprocessos para a produção de diversos produtos de valor agregado. $\mathrm{O}$ mercado para os produtos derivados da biomassa vegetal inclui combustíveis e insumos químicos em geral. Dentre estes, encontram-se alimentos, fármacos e enzimas. Estes materiais lignocelulósicos são compostos principalmente por uma mistura de carboidratos polimerizados (celulose e hemicelulose) e lignina (Fengel, Wegener, 1989). Dentre as diferentes biomassas que compõem os materiais lignocelulósicos os cavacos de eucalipto são fontes promissoras para a bioconversão destes materiais, uma vez que se constituem em resíduo florestal abundante, renovável e de baixo custo (Parajó et al., 1998a). Muitos materiais lignocelulósicos como os resíduos agro-industriais, bagaço de cana (Silva et al., 1998), palha de arroz (Silva, Roberto, 2001), palha de trigo (Nigam, 2001) e os cavacos de eucalipto (Canettieri et al.,
2001) são utilizados como meio de cultivo para a obtenção biotecnológica do xilitol. O processo biotecnológico tornou-se possível com a descoberta de leveduras capazes de metabolizar pentoses (Barbosa et al., 1988), principalmente D-xilose (principal açúcar nos hidrolisados hemicelulósicos). O primeiro passo do metabolismo da xilose é o transporte deste açúcar através da membrana celular. Uma vez dentro da célula, a xilose é reduzida a xilitol pela enzima xilose redutase (EC1.1.1.21) com a participação das coenzimas NADPH ou NADH (Jeffries, 1983). A seguir, o xilitol é excretado para o exterior da célula ou oxidado a xilulose pela enzima xilitol desidrogenase (EC 1.1.1.9), com a participação de NAD+ (Slininger et al., 1987). A xilulose é fosforilada a xilulose 5-fosfato, a qual pode ser convertida em piruvato através do complexo enzimático transcetolase-transaldolase, que faz a conexão entre a via das fosfopentoses e a via EMP (Nolleau et al., 1993). As enzimas xilose redutase e xilitol desidrogenase diferem na especificidade pelas coenzimas $\mathrm{NADPH}, \mathrm{NADH}, \mathrm{NAD}+\mathrm{e} \mathrm{NADP}+$. Este fato foi precur- 
sor na utilização dessa fonte natural para obtenção de vários produtos biotecnológicos, tais como, xilitol (Silva, Roberto, 2001), etanol (Nigam, 2001), proteína microbiana (Almeida e Silva et al., 1995), combustíveis líquidos, tais como 2,3-butanodiol (Grover et al., 1990) e butanol e vários outros produtos que se utilizam das vias das fosfopentoses. O xilitol, produto de interesse neste trabalho, tem poder adoçante similar ao da sacarose, baixo valor calórico e apresenta propriedades clínicas comprovadas como anticariogenicidade, metabolismo por pacientes diabéticos (Aguirre-Zero et al., 1993) e a prevenção de otites (Uhari et al., 1998). Este trabalho descreve a influência da suplementação do hidrolisado hemicelulósico de cavacos de eucalipto com os nutrientes sulfato de amônio, cloreto de cálcio e farelo de arroz, bem como a avaliação da concentração de xilose no hidrolisado, o pH e o tempo de fermentação na produção de xilitol pela levedura Candida guilliermondii FTI 20037.

\section{MATERIAIS E MÉTODOS}

\section{Obtenção e preparo do hidrolisado hemicelulósico}

O hidrolisado hemicelulósico de cavacos de eucalipto foi obtido por hidrólise ácida de cavacos da espécie Eucalyptus grandis de $20 \times 10 \times 5 \mathrm{~mm}$, contendo $29 \%$ de mistura (Almeida e Silva et al., 1995). A razão de cavaco (w/v) e ácido sulfúrico $0,35 \%$ foi de $1: 4,5$, a temperatura $156^{\circ} \mathrm{C}$ e o tempo de hidrólise 27 minutos. Após a hidrólise, o hidrolisado foi concentrado a vácuo a $70^{\circ} \mathrm{C}$, a fim de aumentar a concentração de xilose. $\mathrm{O}$ hidrolisado original e o concentrado foram caracterizados quanto ao $\mathrm{pH}$, concentração dos açúcares (glicose, xilose e arabinose), ácido acético e fenóis. Após a caracterização, o hidrolisado foi submetido ao tratamento pela alteração do $\mathrm{pH}$ (Alves et al., 1998). O pH inicial de 1,9 foi aumentado para 7,0 com $\mathrm{CaO}$, seguido de redução para $\mathrm{pH}$ 5,5 com $\mathrm{H}_{3} \mathrm{PO}_{4}$ e, em seguida, foi tratado com adição de $10 \%$ de carvão ativo sob agitação em shaker a $200 \mathrm{rpm}$ por $1 \mathrm{~h}$ a 30 C. A cada alteração do $\mathrm{pH}$ e também após tratamento com carvão, o precipitado formado foi removido por filtração a vácuo. Finalmente, o $\mathrm{pH}$ do hidrolisado foi ajustado em 4,0 e 8,0, conforme matriz de planejamento fatorial fracionário $2^{6-2} \mathrm{e}$ autoclavado a $11{ }^{\circ} \mathrm{C}$ por 15 minutos.

\section{Microrganismo e Preparação de Inóculo}

A levedura Candida guilliermondii FTI 20037 foi mantida a $4{ }^{\circ} \mathrm{C}$ em ágar extrato de malte inclinado. As células, de 3-5 dias, foram inoculadas em meio de cultura suplementadas com: D-xilose: 30,0 g/L, D-glicose: 7,0 g/L, extrato de farelo de arroz: $20,0 \mathrm{~g} / \mathrm{L},\left(\mathrm{NH}_{4}\right)_{2} \mathrm{SO}_{4}$ : $2,0 \mathrm{~g} / \mathrm{L} \mathrm{e} \mathrm{CaCl}_{2} \cdot 2 \mathrm{H}_{2} \mathrm{O}: 0,1 \mathrm{~g} / \mathrm{L}$. Cinquenta mililitros deste meio foram colocados em erlenmeyer de $125 \mathrm{~mL}$ e incubados em shaker a $200 \mathrm{rpm}, 30{ }^{\circ} \mathrm{C}$ por $24 \mathrm{~h}$. Em seguida, as células foram coletadas por centrifugação $(2000 \mathrm{x} \mathrm{g}$, $15 \mathrm{~min}$ ) e ressuspensa em água destilada esterilizada. Dessa suspensão foi usado um volume adequado $(0,5-1,0 \mathrm{~mL})$ para alcançar a concentração inicial de células de $3.0 \mathrm{~g} / \mathrm{L}$ ou $10^{8}$ células $/ \mathrm{mL}$ em todas as fermentações.

\section{Meio e Condições de Fermentação}

O meio de fermentação utilizado foi o hidrolisado hemicelulósico tratado e suplementado com os nutrientes segundo um planejamento fatorial fracionário $2^{6-2}$. As fermentações foram realizadas em erlenmeyer de $125 \mathrm{~mL}$ contendo $50 \mathrm{~mL}$ de meio em shaker a $200 \mathrm{rpm}, 30{ }^{\circ} \mathrm{C}$, durante 72 ou $96 \mathrm{~h}$.

\section{Métodos Analíticos}

As concentrações de açúcares e ácido acético foram determinadas por cromatografia líquida de alta eficiência (CLAE) - cromatógrafo Shimadzu C-R7A (Kyoto, Japão), equipado com um detector de Índice de Refração (RI) e coluna Aminex HPX-87H Bio-Rad (Hercules, CA) sob as seguintes condições: temperatura: $45^{\circ} \mathrm{C}$, eluente: ácido sulfúrico, $0,01 \mathrm{~N}$, fluxo: $0,6 \mathrm{~mL} / \mathrm{min}$, volume amostra injetado: $20 \mathrm{~mL}$. Para a determinação de fenóis foi utilizado o método colorimétrico (Kim, Yoo, 1996; Guerra, 2000).

\section{Análise Estatística}

Os fatores utilizados nos experimentos, bem como os seus níveis estudados, estão mostrados na Tabela I. A avaliação da influência dos fatores estudados foi realizada de acordo com planejamento fatorial fracionário $2^{6-2} \mathrm{e}$ análise estatística efetuada no programa Statgraphics v. 4.1 e Stat-Ease v. 5.0.

\section{RESULTADOS E DISCUSSÃO}

Na Tabela II são mostradas as características do hidrolisado de cavacos de eucalipto logo após hidrólise ácida (original) e após concentração a vácuo (concentrado). Estes hidrolisados compreendem mistura de monossacarídeos, predominantemente de xilose, característica também constatada nos hidrolisados hemice- 
TABELA I - Fatores e Níveis utilizados no Planejamento fatorial fracionário $2^{6-2}$

\begin{tabular}{lccc}
\hline Fatores & Abreviações & Nível inferior & Nível superior \\
\hline sulfato de amônio $(\mathrm{g} / \mathrm{L})$ & $\mathrm{SA}$ & 1,0 & 3,0 \\
cloreto de cálcio $(\mathrm{g} / \mathrm{L})$ & $\mathrm{CA}$ & 0,0 & 1,0 \\
farelo de arroz $(\mathrm{g} / \mathrm{L})$ & $\mathrm{FA}$ & 5,0 & 20,0 \\
$\mathrm{pH}$ & $\mathrm{pH}$ & 4,0 & 8,0 \\
concentração de xilose $(\mathrm{g} / \mathrm{L})$ & $\mathrm{CO}$ & 15,0 & 45,0 \\
tempo de fermentação $(\mathrm{h})$ & $\mathrm{T}$ & 72 & 96 \\
\hline
\end{tabular}

lulósicos de palha de arroz (Mussato, Roberto, 2001), bagaço de cana (Rodrigues et al.,1999) e palha de trigo (Nigam, 2001).

A Tabela II mostra que todos os compostos analisados tiveram suas concentrações aumentadas após a etapa de concentração a vácuo. Comportamento semelhante foi encontrado por Alves et al. (1998) e Rodrigues et al. (1999) durante a concentração do hidrolisado hemicelulósico de bagaço. Segundo Fengel e Wegener, (1989) a xilose pode ser degradada a furfural durante o processo de concentração, fato que, no presente trabalho, não ocorreu, pois foi observado que o aumento da concentração dos açúcares glicose, xilose e arabinose foi diretamente proporcional ao fator de concentração do hidrolisado (3 vezes). O ácido acético, considerado como forte inibidor da fermentação de xilose-xilitol (Ferrari et al., 1992; Felipe et al., 1996) teve sua concentração elevada de forma não proporcional (1,2 vezes) ao fator de concentração do hidrolisado, provavelmente devido à volatilização parcial na etapa de concentração.

Ainda na Tabela II, observa-se que a concentração a vácuo do hidrolisado acarretou decréscimo do $\mathrm{pH}$ inicial de 1,9 para 1,5. Este fato se deve, provavelmente, ao aumento da concentração de íons $\mathrm{H}^{+}$provenientes do $\mathrm{H}_{2} \mathrm{SO}_{4}$ utilizado na hidrólise ácida e também do $\mathrm{CH}_{3} \mathrm{COOH}$ presente no meio. Os fenóis, outros compostos tóxicos à atividade microbiana, também foram constatados no hidrolisado de eucalipto com concentração de $1,25 \mathrm{~g} / \mathrm{L}$, superior à presente no hidrolisado de bagaço, da ordem de 0,04 g/L encontrado por Rodrigues et al. (2001).

$\mathrm{Na}$ Tabela III são mostradas a matriz de planejamento experimental e a respectiva produção de xilitol. Os resultados experimentais foram utilizados para avaliar a influência dos fatores: SA, CA, FA, pH, CO e T na produção de xilitol. Os níveis inferiores e superiores de $\mathrm{pH}$ e $\mathrm{CO}$ foram corrigidos, pois foi verificada variação entre os valores experimentais e os propostos inicialmente. Os hidrolisados foram acertados para $\mathrm{pH}$ 4,0 (ensaios de 1 a 8) e pH 8,0 (ensaios 9 a 16) no final do tratamento e foi verificado que após a autoclavagem estes valores modificaram, em média, para pH 3,55 e pH 5,72 (conforme é mostrado na Tabela III).

TABELA II - Características do hidrolisado hemicelulósico de cavacos de eucalipto

\begin{tabular}{lcc}
\hline Características & $\begin{array}{c}\text { Hós hidrólise ácida } \\
\text { (original) }\end{array}$ & $\begin{array}{c}\text { Hidrolisado } \\
\text { após concentração a vácuo } \\
\text { (concentrado) }\end{array}$ \\
\hline $\mathrm{pH}$ & 1,9 & 1,5 \\
glicose $(\mathrm{g} / \mathrm{L})$ & 2,54 & 6,50 \\
Xilose $(\mathrm{g} / \mathrm{L})$ & 19,17 & 59,21 \\
Arabinose $(\mathrm{g} / \mathrm{L})$ & 0,41 & 0,98 \\
Ácido acético $(\mathrm{g} / \mathrm{L})$ & 5,03 & 6,33 \\
Fenóis $(\mathrm{g} / \mathrm{L})$ & 1,25 & n.d. \\
\hline
\end{tabular}

n.d. = não determinado 
Tabela III - Matriz de planejamento experimental e a respectiva produção de xilitol para o planejamento fatorial fracionário $2^{6-2}$ com repetição

\begin{tabular}{cccccccc}
\hline Ensaios & SA $(\mathrm{g} / \mathrm{L})$ & $\mathrm{CA}(\mathrm{g} / \mathrm{L})$ & $\mathrm{FA}(\mathrm{g} / \mathrm{L})$ & $\mathrm{PH}$ & $\mathrm{CO}(\mathrm{g} / \mathrm{L})$ & $\mathrm{T}(\mathrm{h})$ & xilitol $(\mathrm{g} / \mathrm{L})$ \\
\hline 1 & 1,0 & 0,0 & 5,0 & 3,57 & 15,64 & 72 & 0,65 \\
2 & 3,0 & 0,0 & 5,0 & 3,47 & 50,38 & 72 & 0,00 \\
3 & 1,0 & 1,0 & 5,0 & 3,45 & 50,33 & 96 & 0,09 \\
4 & 3,0 & 1,0 & 5,0 & 3,52 & 15,34 & 96 & 0,56 \\
5 & 1,0 & 0,0 & 20,0 & 3,49 & 47,79 & 96 & 0,53 \\
6 & 3,0 & 0,0 & 20,0 & 3,70 & 13,95 & 96 & 1,66 \\
7 & 1,0 & 1,0 & 20,0 & 3,66 & 14,69 & 72 & 0,71 \\
8 & 3,0 & 1,0 & 20,0 & 3,52 & 44,60 & 72 & 0,00 \\
9 & 1,0 & 0,0 & 5,0 & 5,93 & 15,25 & 96 & 5,06 \\
10 & 3,0 & 0,0 & 5,0 & 5,73 & 48,63 & 96 & 5,32 \\
11 & 1,0 & 1,0 & 5,0 & 5,78 & 48,08 & 72 & 7,61 \\
12 & 3,0 & 1,0 & 5,0 & 5,92 & 14,05 & 72 & 2,50 \\
13 & 1,0 & 0,0 & 20,0 & 5,60 & 48,08 & 72 & 6,82 \\
14 & 3,0 & 0,0 & 20,0 & 5,59 & 13,56 & 72 & 2,63 \\
15 & 1,0 & 1,0 & 20,0 & 5,57 & 15,10 & 96 & 2,93 \\
16 & 3,0 & 1,0 & 20,0 & 5,61 & 45,08 & 96 & 5,56 \\
\hline
\end{tabular}

Na Figura 1 é mostrado o gráfico de probabilidade normal, onde podemos constatar que os fatores que exerceram efeitos significativos sobre a produção de xilitol foram $\mathrm{pH}, \mathrm{CO}, \mathrm{SA}$ e as interação $[\mathrm{SA}][\mathrm{T}],[\mathrm{SA}][\mathrm{pH}]$ e $[\mathrm{SA}][\mathrm{FA}]$, dispostos fora da reta no gráfico. De acordo com Box et al. (1978) e Barros Neto et al. (1995), os efeitos que se confundem com o erro experimental acumulamse formando uma reta em relação à probabilidade normal acumulada, sendo portanto não significativos. Na Tabela IV é mostrada a análise dos efeitos, a qual confirma os efeitos significativos encontrados na Figura 1 como $\mathrm{pH}$, $\mathrm{CO}$ e $\mathrm{SA}$ e as interações $[\mathrm{SA}][\mathrm{pH}]+[\mathrm{CO}][\mathrm{T}]$ e $[\mathrm{SA}][\mathrm{T}]+[\mathrm{pH}][\mathrm{CO}]$ significativas ao nível de $5 \%$ de probabilidade e $[\mathrm{SA}][\mathrm{FA}]+[\mathrm{CA}][\mathrm{CO}]$ a $10 \%$.

Contudo, os efeitos de interação apresentam-se confundidos e, assim, foi feita uma análise criteriosa para identificar qual a interação que de fato era significativa para o processo. Desprezando as variáveis não significativas, resultou SA, FA, pH e CO. As variáveis presentes na interação, cujo os efeitos principais foram significativos, apresentam grande probabilidade de também serem significativas. Desse modo, foram selecionadas as interações $[\mathrm{SA}][\mathrm{FA}],[\mathrm{SA}][\mathrm{pH}]$ e $[\mathrm{pH}][\mathrm{CO}]$ como significativas, eliminando CA e fixando $\mathrm{T}$ em $72 \mathrm{~h}$.

$\mathrm{Na}$ Tabela $\mathrm{V}$ é mostrada a análise de variância considerando-se somente os efeitos significativos e é confirmado a influência dos fatores acima descritos, sendo, então, significativos: $\mathrm{SA}, \mathrm{pH}, \mathrm{CO}, \mathrm{FA}$ e as interações [SA][FA],

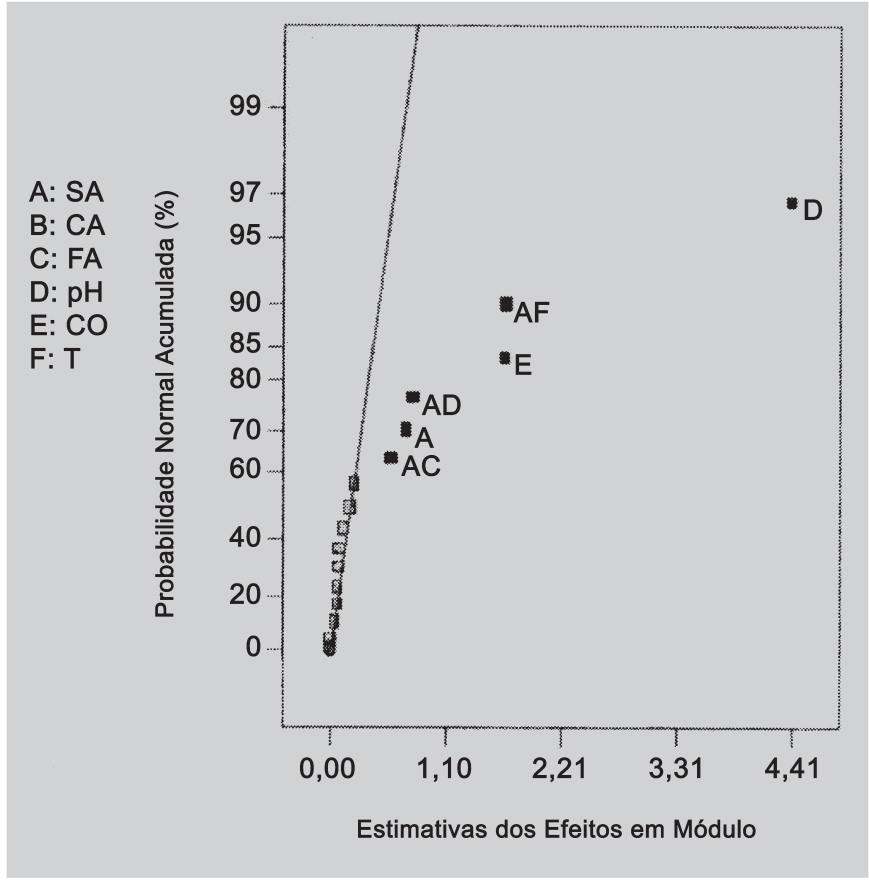

FIGURA 1 - Efeito dos fatores estudados em função da probabilidade acumulada.

$[\mathrm{SA}][\mathrm{pH}]$ e $[\mathrm{pH}][\mathrm{CO}]$. Foram realizados 4 experimentos no ponto central com o objetivo de minimizar o erro experimental e assim identificar o grau do modelo. As repetições permitiram identificar se o modelo é linear ou quadrático. 
TABELA IV - Estimativa dos Efeitos, erros-padrão e teste t de Student na produção de xilitol para o planejamento fatorial fracionário $2^{6-2}$

\begin{tabular}{lccl}
\hline Efeitos & Estimativas & Erros Padrão & t \\
\hline Média & 2,413 & $\pm 0,081$ & - \\
SA & $-0,657$ & $\pm 0,161$ & $4,081 *$ \\
CA & $-0,228$ & $\pm 0,161$ & 1,416 \\
FA & 0,094 & $\pm 0,160$ & 0,588 \\
PH & 3,984 & $\pm 0,148$ & $26,919 *$ \\
CO & 1,363 & $\pm 0,147$ & $9,272 *$ \\
T & 0,043 & $\pm 0,161$ & 0,267 \\
{$[\mathrm{SA}][\mathrm{CA}]+[\mathrm{FA}][\mathrm{CO}]$} & 0,064 & $\pm 0,160$ & 0,400 \\
{$[\mathrm{SA}][\mathrm{FA}]+[\mathrm{CA}][\mathrm{CO}]$} & 0,508 & $\pm 0,161$ & $3,155^{* *}$ \\
{$[\mathrm{SA}][\mathrm{pH}]+[\mathrm{CO}][\mathrm{T}]$} & $-0,762$ & $\pm 0,148$ & $5,149 *$ \\
{$[\mathrm{SA}][\mathrm{CO}]+[\mathrm{CA}][\mathrm{FA}]+[\mathrm{pH}][\mathrm{T}]$} & $-0,258$ & $\pm 0,147$ & 1,755 \\
{$[\mathrm{SA}][\mathrm{T}]+[\mathrm{pH}][\mathrm{CO}]$} & 1,785 & $\pm 0,160$ & $11,156 *$ \\
{$[\mathrm{CA}][\mathrm{pH}]+[\mathrm{FA}][\mathrm{T}]$} & 0,071 & $\pm 0,148$ & 0,480 \\
{$[\mathrm{CA}][\mathrm{T}]+[\mathrm{FA}][\mathrm{pH}]$} & $-0,140$ & $\pm 0,161$ & 0,870 \\
\hline
\end{tabular}

* significativo ao nível de $5 \%$ de probabilidade, $\left(\mathrm{t}_{5}\right)=3,182$

** significativo ao nível de $10 \%$ de probabilidade, $\left(\mathrm{t}_{10}\right)=2,353$

TABELA V - Análise de variância para produção de xilitol estimados no planejamento fatorial $2^{4}$

\begin{tabular}{lcccrc}
\hline Efeitos & Soma dos Quadrados & Grau de liberdade & Quadrado médio & \multicolumn{1}{c}{ F } & P \\
\hline AS & 1,646 & 1 & 1,646 & 9,17 & 0,029 \\
$\mathrm{PH}$ & 65,516 & 1 & 65,516 & 365,09 & 0,000 \\
$\mathrm{CO}$ & 7,223 & 1 & 7,223 & 40,25 & 0,001 \\
{$[\mathrm{SA}][\mathrm{FA}]$} & 1,157 & 1 & 1,157 & 6,45 & 0,052 \\
{$[\mathrm{SA}][\mathrm{pH}]$} & 2,646 & 1 & 2,646 & 14,74 & 0,012 \\
{$[\mathrm{pH}][\mathrm{CO}]$} & 12,294 & 1 & 12,294 & 68,51 & 0,000 \\
Erros & 0,897 & 5 & 0,179 & & \\
Total & 101,698 & 15 & & & \\
\hline
\end{tabular}

$\mathrm{R}^{2}=0,97$

Na Tabela VI são mostrados os resultados da produção de xilitol no ponto central.

TABELA VI - Resultados da produção de xilitol para os experimentos realizados no ponto central

\begin{tabular}{cccccc}
\hline $\begin{array}{c}\text { Ensaios } \\
(\mathrm{g} / \mathrm{L})\end{array}$ & $\begin{array}{c}\mathrm{SA} \\
(\mathrm{g} / \mathrm{L})\end{array}$ & FA & $\begin{array}{c}\mathrm{pH} \\
(\mathrm{g} / \mathrm{L})\end{array}$ & $\begin{array}{c}\mathrm{CO} \\
(\mathrm{g} / \mathrm{L})\end{array}$ & xilitol \\
\hline 1 & 2,0 & 12,5 & 5,32 & 23,25 & 1,96 \\
2 & 2,0 & 12,5 & 5,47 & 22,69 & 1,64 \\
3 & 2,0 & 12,5 & 5,18 & 22,64 & 1,92 \\
4 & 2,0 & 12,5 & 5,30 & 23,70 & 2,17 \\
\hline
\end{tabular}

De acordo com Box et al. (1978) e Barros Neto et al. (1995), um modelo quadrático adequado significa que se está próximo da otimização, então realizam-se ensaios complementares para encontrar os coeficientes de segunda ordem, enquanto que um modelo linear indica que se devem alterar os níveis da região de estudo a fim de se aproximar da otimização, o que se conhece como passo ascendente.

Na Tabela VII é mostrada a análise de variância para um modelo linear e observa-se que embora o coeficiente de determinação, $\mathrm{R}^{2}$, seja igual a 0,92 , os efeitos significativos foram somente $\mathrm{CO}$ e $[\mathrm{pH}][\mathrm{CO}]$, indicando que um modelo quadrático é mais adequado para representar o processo. 
TABELA VII - Análise de variância para os efeitos no planejamento fatorial $2^{4}$, com quatro repetições no ponto central para um modelo linear

\begin{tabular}{lccccc}
\hline Efeitos & $\begin{array}{c}\text { Soma dos } \\
\text { quadrados }\end{array}$ & $\begin{array}{c}\text { Grau de } \\
\text { liberdade }\end{array}$ & Quadrado médio & Teste $\mathrm{f}$ & $\begin{array}{c}\text { Nível de } \\
\text { significância }(\mathrm{p})\end{array}$ \\
\hline $\mathrm{SA}$ & 0,83115 & 1 & 0,83115 & 0,92 & 0,3731 \\
$\mathrm{FA}$ & 0,00013 & 1 & 0,00013 & 0,00 & 0,9908 \\
$\mathrm{pH}$ & 1,75108 & 1 & 1,75108 & 1,93 & 0,1979 \\
$\mathrm{CO}$ & 6,06333 & 1 & 6,06332 & 6,69 & 0,0294 \\
{$[\mathrm{SA}][\mathrm{FA}]$} & 0,80448 & 1 & 0,80448 & 0,89 & 0,3804 \\
{$[\mathrm{SA}][\mathrm{pH}]$} & 2,31311 & 1 & 2,31311 & 2,55 & 0,1445 \\
{$[\mathrm{SA}][\mathrm{CO}]$} & 0,41406 & 1 & 0,41106 & 0,45 & 0,5245 \\
{$[\mathrm{FA}][\mathrm{pH}]$} & 0,25632 & 1 & 0,25632 & 0,28 & 0,6132 \\
{$[\mathrm{FA}][\mathrm{CO}]$} & 0,04309 & 1 & 0,04309 & 0,05 & 0,8345 \\
{$[\mathrm{pH}][\mathrm{CO}]$} & 15,58740 & 1 & 15,58740 & 17,21 & 0,0025 \\
Erros & 8,15355 & 9 & 0,90595 & & \\
total & 103,30208 & 19 & & & \\
\hline
\end{tabular}

$\mathrm{R}^{2}=0,92$

Na Tabela VIII é mostrada uma estimativa da análise para um possível modelo de segundo grau. Constata-se que alguns termos não significativos no modelo linear passam a ser significativos, assim como a curvatura ( $\mathrm{p}=0,0006)$, aumentando ainda o coeficiente de determinação, $\left(\mathrm{R}^{2}\right)$, de 0,92 para 0,98 , confirmando que o modelo quadrático é mais adequado.

Portanto, podemos afirmar que a formação de xilitol a partir do hidrolisado hemicelulósico de cavacos de eucalipto depende dos fatores, sulfato de amônio, farelo de arroz, concentração de xilose no hidrolisado e pH inicial de fermentação. A suplementação de nutrientes no meio de fermentação é primordial, uma vez que proporciona condições para o crescimento do microrganismo. O sulfato de amônio serve como fonte de nitrogênio e o farelo de arroz é fonte de aminoácidos. Ambos os nutrientes favorecem o crescimento da levedura. $\mathrm{O}$ pH também exerce forte influência na bioconversão xilose em xilitol. Segun-

TABELA VIII - Estimativa da Análise de variância para os efeitos do planejamento fatorial $2^{4}$ com quatro repetições no ponto central para um modelo quadrático

\begin{tabular}{lcccrc}
\hline Efeitos & $\begin{array}{c}\text { Soma dos } \\
\text { quadrados }\end{array}$ & $\begin{array}{c}\text { Grau de } \\
\text { liberdade }\end{array}$ & Quadrado médio & Teste f & $\begin{array}{c}\text { Nível de } \\
\text { significância (p) }\end{array}$ \\
\hline SA & 3,19976 & 1 & 3,19976 & 15,11 & 0,0046 \\
FA & 0,01299 & 1 & 0,01299 & 0,06 & 0,8131 \\
PH & 2,55247 & 1 & 2,55247 & 12,05 & 0,0084 \\
$\mathrm{CO}$ & 5,45255 & 1 & 5,45255 & 25,75 & 0,0010 \\
{$[\mathrm{SA}][\mathrm{FA}]$} & 0,77020 & 1 & 0,77020 & 3,64 & 0,0929 \\
{$[\mathrm{SA}][\mathrm{pH}]$} & 2,33581 & 1 & 2,33581 & 11,03 & 0,0105 \\
{$[\mathrm{SA}][\mathrm{CO}]$} & 0,36166 & 1 & 0,36166 & 1,71 & 0,2276 \\
{$[\mathrm{FA}][\mathrm{pH}]$} & 0,11806 & 1 & 0,11806 & 0,56 & 0,4844 \\
{$[\mathrm{FA}][\mathrm{CO}]$} & 0,04740 & 1 & 0,04740 & 0,22 & 0,6537 \\
{$[\mathrm{pH}][\mathrm{CO}]$} & 13,22006 & 1 & 13,22006 & 62,43 & 0,0000 \\
$\mathrm{Curvatura}$ & 6,45938 & 1 & 6,45968 & 30,50 & 0,0006 \\
Erros & 1,69417 & 8 & 0,21177 & & \\
total & 103,602080 & 19 & & & \\
\hline
\end{tabular}

$\mathrm{R}^{2}=0,98$ 
do Pelczar et al. (1980), as leveduras crescem melhor em meios ácidos com pH entre 3,5 e 3,8, sendo que os limites situam-se entre $\mathrm{pH} 2,2$ e 8,0, de acordo com a espécie. Roberto et al. (1996), trabalhando com a levedura $C$. guilliermondii constatou que o $\mathrm{pH}$ inicial do meio afetou a produção de xilitol e obteve melhores resultados com um pH inicial de 5,3. Em estudos realizados com a $C$. shehatae a produção de etanol aumentou de 45 para $55 \mathrm{~g} /$ L quando o pH passou de 4,5 para 6,0 (Kastner et al., 1996). Um outro fator analisado e de grande influência na produção de xilitol foi a concentração inicial de xilose no hidrolisado. Quando concentramos o hidrolisado, no nosso caso a vácuo por evaporação, para aumentarmos a concentração de xilose, ocorre concomitantemente aumento na concentração de outros compostos não-voláteis, alguns deles inibidores do metabolismo microbiano com conseqüente efeito negativo na produção de xilitol. Segundo Parajó et al. (1998b), a elevação da concentração inicial de xilose promove o seu rápido consumo e intensifica a produção de xilitol, resultando em maiores eficiência e produtividade volumétrica. No entanto, o aumento excessivo da concentração de xilose acarreta decréscimo nas taxas de crescimento do microrganismo, com conseqüente queda das taxas de produção de xilitol (Nolleau et al., 1993). Essas interferências negativas na produção de xilitol podem ser explicadas em função da pressão osmótica elevada e da repressão de enzimas que participam do metabolismo deste açúcar (Nigam, Singh, 1995).

\section{CONCLUSÃO}

A obtenção biotecnológica de xilitol a partir de cavacos de eucalipto é influenciada pelos nutrientes sulfato de amônio e farelo de arroz como suplementação do meio de fermentação no hidrolisado, bem como pela concentração de xilose no hidrolisado e pH.

\section{ABSTRACT \\ Xylitol production from eucalyptus chips by biotechnological means}

A hemicellulose fraction was obtained after acid hydrolysis of eucalyptus chips soaked in sulfuric acid. The hydrolysate was used as the substrate to grow Candida guilliermondii FTI 20037. The influence of the nutrients (ammonium sulfate, calcium chloride, rice bran), $p H$, xylose concentration in the eucalyptus chips hemicellulosic hydrolisate and fermentation time were studied indicating that the xylitol production is mainly influenced by nutrients: ammonium sulfate and rice bran; initial $p H$ offermentation and by the xylose concentration in the eucalyptus chips hemicellulosic hydrolisate.

UNITERMS: Eucalyptus hemicellulosic hydrolyzate. Candida guilliermondii FTI 20037. Fermentation. Xylitol.

\section{AGRADECIMENTOS}

Os autores agradecem à Fundação de Amparo à Pesquisa do Estado de São Paulo (FAPESP) pelo auxílio financeiro.

\section{REFERÊNCIAS BIBLIOGRÁFICAS}

AGUIRRE-ZERO, O., ZERO, D. T., PROSKIN, H. M. Effect of chewing xylitol chewing gum on salivary flow rate and the acidogenic potencial of dental plaque. Caries Res., Basel, n.27, p.55-59, 1993.

ALMEIDA e SILVA, J. B., MANCILHA, I. M., VANNETTI, M. C. D., TEIXEIRA, M. A. Microbial protein production by Paecilomyces variotii cultivated in eucalyptus hemicellulosic hydrolyzate. Bioresour. Technol., New York, v.52, p.197-200, 1995.

ALVES, L. A., FELIPE, M. G. A., ALMEIDA E SILVA, J. B., SILVA, S. S., PRATA, A. M. R. Pretreatment of sugarcane bagasse hemicellulose hydrolysate for xylitol production by Candida guilliermondii. Appl. Biochem. Biotechnol., Clifton, v.70-72, p. 89-98, 1998.

BARBOSA, M. F. S., MEDEIROS, M. B., MANCILHA, I. M., SCHNEIDER, H., LEE, H. Screening of Yeasts for Production of Xylitol from D-Xylose and some factors which affect Xylitol yield in Candida guilliermondii. J. Ind. Microbiol., Amsterdan, v.3, p. 241-251, 1988.

BARROS NETO, B., SCARMINIO, I. S., BRUNS, R. E. Planejamento e otimização de experimentos. Campinas: Editora UNICAMP, 1995. 299p.

BOX, G. E. P., HUNTER, W. G., HUNTER, J. S. Statistics for experimenters: an introduction to design, data analysis and model building. New York: John Wiley \& Sons Inc., 1978. 653p.

CANETTIERI, E. V., ALMEIDA e SILVA, J. B., FELIPE, M. G. A. Application of Factorial Design to the study of xylitol production from Eucalyptus Hemicellulosic Hydrolysate. Appl. Biochem. Biotechnol., Clifton, v.94, n.2, p. 159-168, 2001. 
GROVER, B. P., GARG, S. K., VERMA, J. Production of 2,3 butanediol from wood hydrolysate by Klebsiela pneumoniae. World J. Microbiol. Biotechnol., London, v.6, p. 328-332, 1990.

GUERRA, A., FERRAZ, A. COTRIM, A., SILVA, F. T. Polymerization of lignin fragments contained in a model effluent by polyphenoloxidases and horseradish peroxidase/hydrogen peroxidase. Enzyme Microb. Technol., Haywards Health, v. 26, p. 315- 323, 2000.

FELIPE, M. G. A., ALVES, L. A., SILVA, S. S., ROBERTO, I. C., MANCILHA, I. M., ALMEIDA e SILVA, J. B. Fermentation of eucalyptus hemicellulosic hydrolysate to xylitol by Candida guilliermondii. Bioresour. Technol., New York, v. 56, p. 281-283, 1996.

FENGEL, D. ,WEGENER, G. Wood chemistry ultrastructure reactions. Berlin: Walter de Gruyter, 1989. $610 \mathrm{p}$

FERRARI, M. D., NEIROTTI, E., ALBORNOZ, C., SAUCEDO, E. Ethanol production from eucalyptus wood hemicellulose hydrolysate by Pichia stipitis. Biotechnol. Bioeng., Berlin, v.40, p. 753-759, 1992.

JEFFRIES, T. W. Utilization of xylose by bacteria, yeasts and fungi. Adv. Biochem. Eng., Berlin, v.27, p. 1-32, 1983.

KASTNER, J. R., ROBERTS, R. S., JONES, W. J. Effect of $\mathrm{pH}$ on cell viability and product yields in D-xylose fermentations by Candida shehatae. Appl. Microbiol. Biotechnol., Berlin, v.45, p. 224-228, 1996.

KIM, Y. H. , YOO, Y. J. Peroxidase production from carrot hairy root cell culture. Enzyme Microb. Technol., Haywards Heath, v.18, p. 531-535, 1996.

MELAJA, A. J., HÄMÄLÄINEN, L. Process for Making Xylitol U.S. Patent n. 4.008.285. 18 jun.1975. 15 fev. 1977.

MUSSATTO, S. I., ROBERTO, I. C. Hydrolysate detoxification with activated charcoal for xylitol production by Candida guilliermondii. Biotechnol. Lett., Kew, v.23, p.1681-1684, 2001.

NIGAM, J. N. Ethanol production from wheat straw hemicellulose hydrolysate by Pichia stipitis. $J$. Biotechnol., Amsterdam, v.87, n.1, p.17-27, 2001.
NIGAM, P., SINGH, D. Processes for fermentative production of xylitol - a sugar substitute. Process Biochem., New York, v. 30, p. 117-124, 1995.

NOLLEAU, V., PREZIOSI-BELLOY, L., DELGENES, J. P., DELGENES, J. M. Xylitol production from xylose by two yeast strains: Sugar tolerance. Curr. Microbiol., New York, v.27, p.191-7, 1993.

PARAJÓ, J. C.; DOMÍNGUEZ, H.; DOMÍNGUEZ, J. M. Biotechnological production of xylitol - Part 3 : Operation in culture media made from lignocellulose hydrolysates. Bioresour. Technol., New York, v.66, p. 2540, 1998a.

PARAJÓ, J. C.; DOMÍNGUEZ, H.; DOMÍNGUEZ, J. M. Biotechnological Production of Xylitol - Part 2: Operation in culture media made from lignocellulose hydrolysates. Bioresour. Technol., New York, v.65, p. 203-212, 1998b.

PELCZAR, M., REID, R., CHAN, E. C. S. Microbiologia. São Paulo: Mc Graw Hill, 1980, v.1, 566p.

ROBERTO, I. C., SILVA, S. S., FELIPE, M. G. A., MANCILHA, I. M., SATO, S. Bioconversion of Rice Straw Hemicellulose Hydrolysate for the Production of xylitol. Appl. Biochem. Biotechnol., Clifton, v.57/58, p. 339-347, 1996.

RODRIGUES, R. C. L. B., FELIPE, M. G. A., ALMEIDA e SILVA, J. B., VITOLO, M., GÓMEZ, P. V. The influence of $\mathrm{pH}$, temperature and hydrolyzate concentration on the removal of volatile and nonvolatile compounds from sugarcane bagasse hemicellulosic hydrolyzate treated with activated charcoal before or after vacuum evaporation. Braz. J. Chem. Eng., Campinas, v.18, n.3, p.299-311, 2001.

RODRIGUES, D. C. G. A., SILVA, S. S., FELIPE, M. G. A. Fed-batch culture of Candida guilliermondii FTI 20037 for xylitol production from sugar cane bagasse hydrolysate. Lett. Appl. Microbiol., v.29, p. 359-363, 1999.

SILVA, S. S., FELIPE, M. G. A., MANCILHA, I. M. Factors that Affect the Biosynthesis of Xylitol by XyloseFermenting Yeasts. - A Review. Appl. Biochem. Biotechnol., Clifton, v. 70-72, p. 1-9, 1998. 
SILVA, C. J., ROBERTO, I. C. Improvement of xylitol production by Candida guilliermondii FTI 20037 previously adapted to rice straw hemicellulosic hydrolysate. Lett. Appl. Microbiol., Oxford, v.32, n.4, p. 248-52, 2001.

SLININGER, P. J., BOLEN, P. L., KURTZMAN, C .P. Pachysolen tannophilus: Properties and process consideration for ethanol production from D-xylose. Enzyme Microb. Technol., Haywards Health, v.9, p.5-15, 1987.
UHARI, M., KONTIOKARI, T., NIEMELA, M. A novel use of xylitol sugar in preventing acute otitis media. Pediatrics, v. 102, p. 878-884.

Recebido para publicação em 15 de fevereiro de 2001. 